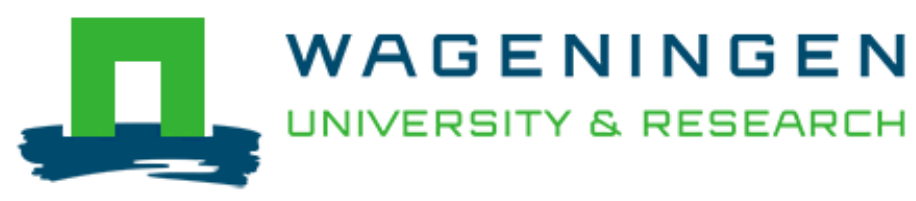

\title{
Soil structure formation and organic matter distribution as affected by earthworm species interactions and crop residue placement
}

Frazao, J. F. T. A., de Goede, R. G. M., Capowiez, Y., \& Pulleman, M. M.

This is a "Post-Print" accepted manuscript, which has been published in "Geoderma"

This version is distributed under a non-commercial no derivatives Creative Commons (c) $(1) \Theta \Theta$

c) ${ }_{\text {w we wo }}(\mathrm{CC}-\mathrm{BY}$-NC-ND) user license, which permits use, distribution, and reproduction in any medium, provided the original work is properly cited and not used for commercial purposes. Further, the restriction applies that if you remix, transform, or build upon the material, you may not distribute the modified material.

Please cite this publication as follows:

Frazao, J. F. T. A., de Goede, R. G. M., Capowiez, Y., \& Pulleman, M. M. (2018). Soil structure formation and organic matter distribution as affected by earthworm species interactions and crop residue placement. Geoderma. DOI:

10.1016/j.geoderma.2018.07.033

You can download the published version at:

https://doi.org/10.1016/i.geoderma.2018.07.033 


\section{Soil structure formation and organic matter distribution as affected by}

\section{earthworm species interactions and crop residue placement}

Joana Frazão, Ron G. M. de Goede, Yvan Capowiez, Mirjam M.

\section{Pulleman}

This is a "Post-Print" accepted manuscript, which has been published in "Geoderma".

This version is distributed under the Creative Commons Attribution 3.0 Netherlands License, which permits unrestricted use, distribution, and reproduction in any medium, provided the original work is properly cited.

Please cite this publication as follows:

Frazão, J.; de Goede, R.G.M.; Capowiez, Y.; Pulleman, M.M. (2018) Soil structure formation and organic matter distribution as affected by earthworm species interactions and crop residue placement. Geoderma xx xx:xx

You can download the published version at:

https://doi.org/10.1016/i.geoderma.2018.07.033 
1 Soil structure formation and organic matter distribution as affected by

2 earthworm species interactions and crop residue placement

4 Joana Frazão ${ }^{\text {a,* }}$, Ron G. M. de Goede ${ }^{\text {a }}$, Yvan Capowiez ${ }^{\text {b }}$, Mirjam M.

5 Pulleman ${ }^{\text {a, c }}$

6 a Department of Soil Quality, Wageningen University, P.O. Box 47, 6700 AA Wageningen,

7 The Netherlands

$8{ }^{\mathrm{b}}$ INRA - unité (Plantes et Systèmes Horticoles), Domaine Saint Paul, 84914 Avignon Cedex

9 09, France

$10{ }^{\mathrm{c}}$ International Center for Tropical Agriculture (CIAT), Km 17 Recta Cali-Palmira, Apartado

11 Aéreo 6713, Zip code: 763537 Cali, Colombia

12 * Corresponding author: joana.fta.frazao@gmail.com

13 Running headline: Earthworm response to food placement and effects on soil structure and

14 organic matter

15 Key-words: Aggregate stability, Soil porosity, Particulate organic matter, Lumbricus

16 terrestris, Lumbricus rubellus, Aporrectodea caliginosa 


\section{Abstract}

Earthworms play an important role in soil organic matter (SOM) dynamics and soil structure formation, including soil porosity and aggregate stability. Earthworms feed on organic inputs such as crop residues (CR) which are displaced by mouldboard ploughing. In a 61-day mesocosm experiment, we investigated the effects of CR placement (surface-applied vs. incorporated) and different earthworm species (combinations) on: 1) the survival and biomass of the earthworm species Lumbricus terrestris, L. rubellus, and Aporrectodea caliginosa, representing anecic, epigeic and endogeic ecological groups, respectively; and 2) earthwormmediated soil structure formation. Earthworms were present either as single species or as species mixtures combining anecics with each of the other groups. Incorporating CR reduced biomass of surface-feeders (L. terrestris: $-30 \%$ of initial body weight vs. $-9 \%$ when CR were surface-applied; L. rubellus: $-74 \%$ vs. $-24 \%$, respectively). L. rubellus survival was also lower when CR were incorporated (50\%) than when CR were surface-applied (92\%). In surfaceapplied CR treatments, the amount of particulate organic matter $(\mathrm{POM})>250 \mu \mathrm{m}$ in the soil profile was positively affected by $L$. terrestris in the soil upper $20 \mathrm{~cm}$ by $16.5 \%$. A similar but weaker effect was found when CR were incorporated (9\% increase). Large water-stable macroaggregates (>2000 $\mu \mathrm{m}$ ) increased in the upper $20 \mathrm{~cm}$ soil only when CR were surfaceapplied and L. terrestris was present (from 2.7 to $13.1 \mathrm{~g} \mathrm{~kg}^{-1}$ ). Small water-stable aggregates increased with functional groups interactions at all soil depths, irrespective of the CR placement. Surface-applied CR increased soil porosity at 2.5-10 cm depth. Large water-stable macroaggregate formation by earthworms was hampered through the incorporation of CR, although CR incorporation increased porosity between 2.5 and $30 \mathrm{~cm}$ soil depth despite reduced earthworm biomass. Furthermore, small macroaggregate formation was hampered by single species, whereas combining functional groups stimulated their formation. Under field conditions residue incorporation might result in trade-offs between the contribution of 
42 surface-feeding earthworms to soil porosity and i) their fitness, as surface-feeding

43 earthworms' body weight loss was larger than when crop residues were surface-applied; as

44 well as ii) large water-stable macroaggregates formation, as no increase in those was found 45 when CR was incorporated. 


\section{Introduction}

Earthworms have long been recognized as soil ecosystem engineers (Jones et al., 1994; Lavelle et al., 1997). Their feeding, burrowing and casting activities strongly impact organic matter distribution and soil structure, thereby modifying soil porosity (Capowiez et al., 2015; Martin, 1982; Pérès et al., 2010), soil aggregate stability (Bossuyt et al., 2006; Hedde et al., 2013), soil organic matter (SOM) dynamics (Pulleman et al., 2003), nutrient availability (van Groenigen et al., 2014), water infiltration (Andriuzzi et al., 2015), soil aeration (Lemtiri et al., 2014) and soil fertility (Syers and Springett, 1984).

Based on their feeding habits and morphological features, Bouché (1977) classified earthworms into three main ecological groups, which reflect their burrowing and feeding habits. He distinguished anecics as detritivores feeding at the soil surface and digging deep vertical permanent burrows, epigeics also as feeding on fresh organic matter at the soil surface, but not commonly associated with burrowing activities, and finally endogeics as geophagous species obtaining their nutrition from organic matter associated to soil mineral particles and being reported to burrow horizontally, creating temporary burrows. In Dutch agricultural soils, the most common species belonging to these groups are, respectively, Lumbricus terrestris (Linné, 1758), Lumbricus rubellus (Hoffmeister, 1843), although some authors have classified this species as epi-endogeic (Hendrix et al., 1999) or epi-anecic (Briones and Álvarez-Otero, 2018), and Aporrectodea caliginosa (Savigny, 1826) (Crittenden et al., 2014; Frazão et al., 2017). L. terrestris, although common in pastures, is less common in arable fields, while farmers are very keen on stimulating this species due to its important role in soil structure formation and water infiltration.

In arable fields, management activities have been reported to affect earthworm communities, in particular ploughing, through mechanical soil disturbance and burial of crop residues (Chan, 2001; Crittenden et al., 2014; Ernst and Emmerling, 2009). Soil inversion due to 
ploughing can destroy anecic earthworm burrows. Re-establishing their burrow system occurs at the high cost of energetic investment of individual earthworm specimens (e.g. Petersen and Luxton (1982) who accounted that during soil modification earthworms respired 74-91\% of assimilated carbon). Also, soil tillage, especially soil inversion, displaces crop residues to deeper soil layers, typically to about 20 to $30 \mathrm{~cm}$ soil depth in case of mouldboard ploughing. Tillage intensity has been found to negatively affect abundances of anecics and epigeics, but have neutral or positive effects on endogeics (Crittenden et al., 2014; de Oliveira et al., 2012; Ernst and Emmerling, 2009), despite increased exposure to predation risks in the short term (Cuendet, 1983). Thus, earthworm communities in agricultural land are subjected to complex interactions involving factors like crop residue management, changes in microclimate, exposure to predation and burrow destruction. Apart from these human-related factors, complex soil-mediated interactions such as interspecific competition and facilitation can affect their survival and growth (Uvarov, 2009).

Competition or facilitation among earthworm species that share or have contrasting feeding habits has been demonstrated in several studies (Lowe and Butt, 1999; 2002; 2003). These interspecific interactions may have consequences for soil structure formation, e.g., soil porosity (Capowiez et al., 2001) and aggregate stability, and SOM availability in arable agroecosystems. Moreover, the distribution of crop residues may affect the feeding behaviour of earthworm species which in turn, is likely to affect their contribution to soil structure formation (Coq et al., 2007). Indeed, several studies have shown that crop residue placement affected the specific contribution of earthworm species to soil porosity (Le Couteulx et al., 2015), SOM dynamics (Giannopoulos et al., 2010; Paul et al., 2012) and aggregate stability (Bossuyt et al., 2006). So far, these studies were restricted to either one or two soil structural features and often focussed on single species effects. Efforts to relate soil porosity, aggregate stability and SOM distribution with earthworm species of the three distinct ecological groups 
and their interactions, under different crop residue placement in the soil profile have been absent, to the best of our knowledge.

The objectives of this study were two-fold. First, we addressed the effects of applying crop residues on the soil surface $v s$. incorporating them in the soil profile, simulating no-tillage and conventional ploughing, respectively, on the survival and body weight of single earthworm species representing the three ecological groups. Furthermore, we focussed on species mixtures' survival and weight change: anecics were combined with either epigeic or endogeic species. Second, we investigated how crop residue placement and earthworm species (interactions) influenced soil porosity, SOM distribution and aggregate stability.

We hypothesized that incorporation of crop residues would have strong negative effects in single species treatments on surface feeders' (model species: L. terrestris and L. rubellus), but not on soil feeders' (model species: A. caliginosa) body weight and survival. Furthermore, we expected that interspecific competition (expressed in weight loss) would occur in the case of mixtures of species with similar feeding habits (L. terrestris combined with L. rubellus), whereas facilitation (expressed in weight gain) would take place when contrasting feeding guilds were combined in earthworm species mixtures (A. caliginosa with L. terrestris). Finally, we hypothesized that i) when crop residues were surface-applied, L. terrestris would cause increased soil porosity, SOM incorporation and stable macroaggregates, aided by endogeic (A. caliginosa) and counteracted by epigeic species (L. rubellus), and that ii) when crop residues were incorporated soil porosity would be higher, but regardless of the species under focus, and with larger weight loss for surface-feeders, especially L. rubellus.

\section{Materials and methods}

\subsection{Experimental set up}


120 A mesocosm experiment (61 days) was performed in the greenhouse to compare earthworm

121 effects on SOM, aggregate stability and soil porosity, when providing crop residues either at

122 the soil surface (simulating no-tillage) or incorporated between 20 and $30 \mathrm{~cm}$ deep

123 (simulating conventional tillage by mouldboard ploughing). The experimental duration was

124 chosen as a compromise between logistical constraints and expected effects (e.g. Le Couteulx

125 et al. (2015) found earthworm-derived porosity effects after 60 days of experimental time).

126 The earthworm effects considered here focussed on the three ecological groups (anecic,

127 epigeic and endogeic) and interactions between anecics and epi- and endogeics. Each

128 ecological group was represented by one model species only, as financial constraints

129 hampered replicating the experimental set-up to consider more species within each group.

130 Single species earthworm treatments were Lumbricus terrestris (LT), Aporrectodea

131 caliginosa (AC), and Lumbricus rubellus (LR), two-species treatments were L. terrestris with

132 A. caliginosa (LT+AC) and L. terrestris with L. rubellus (LT+LR) and an additional

133 earthworm-free control treatment (0) was considered as well (Figure 1). The focus on the

134 interactions between L. terrestris and the other two species was triggered by farmers' large

135 interest in the anecics, which mitigate the negative effects of intense rainfall events on e.g.,

136 plant growth (Andriuzzi et al., 2015). Crop residues used were a mixture of winter wheat

137 (Triticum aestivum) stubble and straw and radish (Raphanus sativus subsp. oleiferus),

138 corresponding to commonly used main and cover crops in the Netherlands. Stubble, straw and

139 radish were chopped roughly to $2 \mathrm{~cm}$ and provided to each mesocosm in the following

140 amounts: $4.7 \mathrm{~g}, 14.2 \mathrm{~g}, 5.1 \mathrm{~g}$, respectively, corresponding to $0.4 \mathrm{tha}^{-1}, 1.3$ and $0.5 \mathrm{t} \mathrm{ha}^{-1}$. The

141 experiment was set up in a completely randomized block design with four replicates.

142 Each experimental unit (mesocosm) had a total height of $49.5 \mathrm{~cm}$ and a diameter of $19 \mathrm{~cm}$.

143 Four PVC rings with heights of 12, 20, 10, and $7.5 \mathrm{~cm}$ (Figure 1) were mounted on top of

144 each other using duct-tape. Each column was closed at the bottom. In order to prevent 
earthworms from escaping two parallel $1 \mathrm{~cm}$ wide strips of velcro were glued on the inside of

146 the column, a few cm below the top (Lubbers and van Groenigen, 2013). Additionally, each

147 column was covered with a cotton cloth allowing gas exchange, and attached with a rubber

148 band. Calcareous marine loam soil (de Bakker and Schelling, 1966) was collected from a

149 conventionally tilled arable field of the Westmaas experimental farm of Wageningen

150 University and Research, located in the southwest of The Netherlands. Soil (36.9 $\mathrm{g} \mathrm{OM} \mathrm{kg}^{-1}$,

$151 \mathrm{pH}$ of 7.9 and a texture of $48 \%$ sand and $25 \%$ clay) was collected to a depth of $20 \mathrm{~cm}$, sieved

152 through a 4-mm screen, air-dried at $25^{\circ} \mathrm{C}$ and thoroughly mixed to guarantee homogeneity.

153 Nine days prior to the inoculation of earthworms, each column was packed with $12.5 \mathrm{~kg}$ air-

154 dried soil at a bulk density of $1.20 \mathrm{~g} \mathrm{~cm}^{-3}$ resulting in a total depth of $37.5 \mathrm{~cm}$. Each ring was

155 filled independently ensuring the same bulk density throughout the whole column. The upper

156 ring did not contain soil, but only the crop residues in surface-applied treatments (Figure 1).

157 Crop residues were either incorporated in the profile between 20 and $30 \mathrm{~cm}$ deep, by mixing

158 them thoroughly with the soil prior to filling that PVC ring or applied on the soil surface after

159 the complete column was filled. Gravimetric soil moisture was brought to $234 \mathrm{~g} \mathrm{~kg}^{-1}$ of soil,

160 corresponding to $65 \%$ of water-filled pore space (WFPS) and was adjusted gravimetrically

161 once a week to maintain the soil moisture constant by applying tap water at the soil surface.

162 All columns were incubated at a constant temperature of $15.5^{\circ} \mathrm{C}$ and a light cycle of $15 \mathrm{hrs}$

163 light/9 hrs dark.

164 Three to four weeks prior to the inoculation of earthworms, (sub)adult individuals of $L$.

165 terrestris were commercially obtained from Starfood (Barneveld, The Netherlands), whereas

166 adults of A. caliginosa and L. rubellus were sampled in parks in the vicinity of Wageningen

167 University and Research Centre. Earthworms were kept in plastic containers at $2{ }^{\circ} \mathrm{C}$ with the

168 same soil used as in the experiment and were fed with alder leaves. Two days prior to the

169 inoculation of earthworms in each block, individuals of each species were placed in clean 
170 plastic pots at $16{ }^{\circ} \mathrm{C}$ with moist kitchen paper to allow them to void their guts and their initial

171 body weights were recorded to $0.1 \mathrm{~g}$ accurately. Treatments with $L$. terrestris (LT, LT+AC

172 and $\mathrm{LT}+\mathrm{LR}$ ) received three individuals of $L$. terrestris with total weight of about $15 \mathrm{~g}$,

173 treatments with L. rubellus (LR and LT+LR) received three individuals of L. rubellus with

174 total weight of about $2 \mathrm{~g}$ and treatments with A. caliginosa (AC and $\mathrm{LT}+\mathrm{AC}$ ) received four

175 individuals of L. rubellus with total weight of about $1 \mathrm{~g}$ (Table A1). A. caliginosa numbers

176 were based on field data (e.g., Crittenden et al., 2015) and as L. rubellus and L. terrestris

177 occur usually in lower densities, their experimental density was reduced compared to $A$.

178 caliginosa. However, to ensure that survival rates would be workable, their number could not

179 be lower than three individuals. To avoid earthworms burrowing down along the PVC walls

180 of the mesocosm, they were placed under a $10 \mathrm{~cm}$ diameter plastic cup in the centre of the

181 surface area of each column. In the surface-applied crop residue treatments, residues were

182 carefully put aside for the earthworm inoculation, but spread evenly after the individuals had

183 burrowed in the soil.

\subsection{X-Ray tomography $(X R T)$}

185 Sixty-one days after the inoculation of the earthworms, two replicates of the single-species

186 and no species treatments of both crop residue placement treatments were scanned with X-

187 Ray computed tomography. Scans were executed using the v[tome]x m (Phoenix X-

188 ray/General Electric), with a directional X-Ray tube and a tungsten target. The voltage was set

189 to $200 \mathrm{kV}$ with a current of $30 \mu \mathrm{A}$ with a subsequent power of the Tungsten-target of $60 \mathrm{~W}$.

190 The columns were positioned at $409.022 \mu \mathrm{m}$ from the target, which corresponds to a voxel

191 size of $230 \mu \mathrm{m}$. Because the columns were too tall for a single vertical image, the multi-scan

192 option was selected. Projection images of each experimental unit were taken at 1000

193 equidistant rotation angles between $0^{\circ}$ and $360^{\circ}$. Each image's acquisition time was $333 \mathrm{~ms}$, 
194 with a total time of 33 min for each experimental unit. After the scans were completed, the

195 experimental units were harvested destructively to collect earthworms and soil samples for 196 further analysis (see below).

197

\subsubsection{Soil porosity}

Images were first transformed into 8-bit format. Greylevel histograms showed two wellseparated peaks (one for porosity and one for the soil matrix) and thus images were binarized with the same threshold value. The distribution of porosity with depth was computed for each image as the sum of the areas of all the pores for one image. Total porosity was then calculated for four soil layers (2.5-10, 10-20, 20-30 and 30-35 cm). The upper and lower 2.5 $\mathrm{cm}$ were excluded to ensure a clear characterization of the porosity. Since the soil was sieved to $4 \mathrm{~mm}$, the porosity in the images had two origins: burrows and inter-aggregate porosity, the first being dominant. We assumed that the inter-aggregate porosity was similar for all the cores and thus we subtracted the porosity observed in the control cores without earthworms to the porosity for each soil layer.

\subsection{Destructive sampling}

Surface crop residues and surface casts were carefully removed from each column and ovendried at $35^{\circ} \mathrm{C}$. Each of the four PCV rings comprising one column were cut horizontally and separated, before the start of the measurements. We double-checked soil moisture contents using a sensor, TRIME PICO 64, IMKO (16 cm long sensor rods) inserted at $0 \mathrm{~cm}$ and at 20 $\mathrm{cm}$ depth, and bulk density by measuring twice the height and diameter of the soil within each PVC ring, weighing and correcting for the water content. Next, earthworms were carefully removed from the soil, while gently crumbling the soil into aggregates along natural planes of weakness and passing them through a $12 \mathrm{~mm}$ mesh, before drying at $35^{\circ} \mathrm{C}$. Earthworms were placed at $16{ }^{\circ} \mathrm{C}$ for $48 \mathrm{hrs}$ allowing them to void their guts. Each individual was cleaned, 
excess water was removed with a tissue, and its body weight was recorded. Representative

219 soil subsamples were taken for i) SOM fractionation and ii) aggregate stability measurements.

220 SOM fractionation was done for each depth layer, i.e. $0-20 \mathrm{~cm}, 20-30 \mathrm{~cm}$ and $>30 \mathrm{~cm}$ and the

221 surface casts. However, as the amount of cast material was very small, especially in the case

222 of A. caliginosa mesocosms, casts were pooled per treatment among blocks. Aggregate

223 stability was measured for 0-20 and $20-30 \mathrm{~cm}$ soil layers, and not for casts, as not enough cast

224 material was available after the SOM fractionation.

\subsection{SOM fractions}

Between 80 and $100 \mathrm{~g}$ of soil was dispersed with $300 \mathrm{ml}$ of $0.5 \%$ solution of NaHMP $\left(5 \mathrm{~g} \mathrm{l}^{-1}\right)$

in a shaker overnight. In the case of surface casts the complete sample was used, which

ranged from 25 to $80 \mathrm{~g}$. The total soil suspension was sieved through three mesh sizes to

obtain SOM and mineral soil material of three size fractions: larger than $250 \mu \mathrm{m}$ (particulate organic matter $(\mathrm{POM})$ plus coarse sand $>250 \mu \mathrm{m}$ : $\mathrm{POM}>250)$, between 53 and $250 \mu \mathrm{m}$ (POM plus fine sand $53-250 \mu \mathrm{m}$ : POM 53-250) and silt and clay sized soil particles (SOM plus silt and clay $<53 \mu \mathrm{m}: \mathrm{SOM}<53)$. After the three size fractions were dried at $105^{\circ} \mathrm{C}$ overnight, loss of ignition (LOI) was used to determine the organic matter content of each size

234 fraction $(\mathrm{POM}>250, \mathrm{POM} 53-250$ and $\mathrm{SOM}<53)$.

\subsection{Aggregate stability}

236 Between 30 to $40 \mathrm{~g}$ of soil subsample was used to determine water-stable aggregates (WSA) 237 using the modified wet sieving method of Six et al. (2002), based on Elliott (1986). Three

238 WSA classes of soil aggregates were obtained: large macro-aggregates (WSA > $2000 \mu \mathrm{m}$ :

239 WSA > 2000), small macro-aggregates (WSA 250 - $2000 \mu \mathrm{m}$ : WSA 250-2000), micro240 aggregates (WSA $53-250 \mu \mathrm{m}$ : WSA 53-250) and the silt and clay fraction ( $\mathrm{SC}<53 \mu \mathrm{m}$ SC < 241 53). To obtain these, each soil subsample was placed on a $2 \mathrm{~mm}$ sieve and submerged in 
242 demi-water and left to slake for five minutes. In the following two minutes, the sieve was

243 moved up and down 50 times to allow water and soil particles to go through the mesh. With

244 the material that had passed through the $2 \mathrm{~mm}$ sieve, the same procedure was repeated using

245 sieves of $250 \mu \mathrm{m}$ and $53 \mu \mathrm{m}$. The fractions collected by the sieves were carefully backwashed

246 to pre-weighed aluminium pans, dried overnight at $105^{\circ} \mathrm{C}$ and weighed. The suspension

247 smaller than $53 \mu \mathrm{m}$ was collected in a bucket, its volume was noted down and a subsample of

248 known volume was dried at $105^{\circ} \mathrm{C}$ and weighed.

\subsection{Statistical analysis}

Earthworm biomass (as percentage of the initial body weight) and survival were calculated per column. The single and interactive effects of crop residue placement and presence of other species (i.e. L. rubellus or A. caliginosa) on the weight change of L. terrestris were examined using linear mixed models with a normal distribution, with block as a random factor. Because the variation of L. terrestris' survival was very low (only three individuals died during the experiment), it was not possible to compute linear mixed models for L. terrestris' survival.

256 For the weight change and survival of $L$. rubellus and A. caliginosa, crop residue placement and presence of $L$. terrestris were considered as fixed effects.

258 The single and interactive effects of L. terrestris (present or absent) and other earthworm species (no species, L. rubellus and A. caliginosa) on SOM size fractions per depth (0-20, 2030 , and $>30 \mathrm{~cm}$ ) and on WSA size classes at 0-20 and 20-30 cm depth were analysed for each 261 crop residue treatment separately, using linear mixed models with a normal distribution, with 262 block as a random factor. For porosity, the fixed effects of the mixed model were slightly different, and corresponded to the (interactive) effects of single earthworm species and soil

264 depth (intervals between 2.5-10, 10-20, 20-0 and 30-35 cm), being analysed separately for 265 each of the crop residue treatments, as well. Porosity was quantified after correcting for inter- 
aggregate porosity of the earthworm-free treatments and expressed as percentage of the total soil volume, and one-tailed T-tests were computed to check whether mean porosity values were larger than zero $(\mathrm{p}<0.05)$. When the overall linear mixed models were statistically significant at the p-level of 0.05 , pairwise comparisons were computed refitting the models with the significant (interactive) fixed effects. P-values adjustments to avoid inflation type I errors were only considered necessary when the interaction between the fixed effects was significant due to the large number of pairwise comparisons (15, in the case of aggregate stability SOM and L. terrestris weight change or survival; 66, in the case of porosity). In that case, Tukey post-hoc adjustments were used. Overall models' distribution and variance assumptions were inspected visually, and if needed, a variance structure was used to avoid heteroscedasticity (Zuur et al., 2009). All analyses were performed with R 3.3.1 (R Core

277 Team, 2014), using packages nlme 3.1-131 and lsmeans 2.27-61.

\section{Results}

\subsection{Earthworm body weight change and survival}

280 All earthworm species lost weight during the 61 days of this experiment, but the extent 281 depended on the treatments, i.e. residue placement and species: L. terrestris lost on average $28230 \%$ of the initial weight when residues were incorporated in the profile, and only $9 \%$ when 283 surface-applied ( $<<0.0001)$, and L. rubellus presented a similar, but stronger pattern $(74 \%$ 284 vs. $24 \%, \mathrm{p}=0.003$, Table 1). Body mass of $L$. rubellus was reduced by the presence of $L$. 285 terrestris, irrespective of crop residue placement (-35\% when alone vs. $-63 \%$, when together 286 with $L$. terrestris, $\mathrm{p}=0.001$, Table 1). Earthworm survival was rather high, particularly for $L$. 287 terrestris (> 90\%) and A. caliginosa (> 80\%). Survival of L. rubellus was higher when 288 residues were surface-applied as compared to incorporated into the soil profile (92\% vs. 50\%, 
$\mathrm{p}=0.039$, Table 1 ). Besides an overall body mass loss of $19-29 \%$ during the experiment, $A$.

290 caliginosa body weight or survival did not differ between the treatments (Table 1).

291

292

293

294

295

296

297

298

299

300

301

302

303

304

305

306

307

308

309

310

311

\subsection{SOM fractions}

When residues were surface-applied, SOM fractions were affected by L. terrestris at 0-20 and 20-30 cm depth and by L. rubellus at 20-30 cm, whereas neither A. caliginosa nor the interaction between both earthworm treatments affected SOM distribution. L. terrestris increased POM > 250 at 0 to $20 \mathrm{~cm}$ soil depth by $16.5 \%$, from $1.09( \pm 0.03)$ to $1.27( \pm 0.06) \mathrm{g}$ $\mathrm{kg}^{-1}(\mathrm{p}=0.014)$, irrespective of the presence of other species (Table 2), and decreased SOM < 53 at 20 to $30 \mathrm{~cm}$ soil depth by $5 \%$, from $34.02( \pm 0.62)$ to $32.32( \pm 0.37) \mathrm{g} \mathrm{kg}^{-1}$ (overall model $\mathrm{p}=0.005$, Table 2). L. rubellus, irrespective of the presence of L. terrestris, increased POM 53-250 at 20 to $30 \mathrm{~cm}$ soil depth by $26 \%$, from $2.54( \pm 0.11)$ to $3.20( \pm 0.17) \mathrm{g} \mathrm{kg}^{-1}$ (pairwise $\mathrm{p}=0.010$, Table 2 ).

When crop residues were incorporated at 20 to $30 \mathrm{~cm}$ depth, L. terrestris increased POM > 250 in the $0-20$ soil layer by $9 \%$, from $0.98( \pm 0.01)$ to $1.07( \pm 0.03) \mathrm{g} \mathrm{kg}^{-1}(\mathrm{p}=0.043$, Table 3), but the effect was smaller than in the surface-applied residue treatments. At $20-30 \mathrm{~cm}$ depth POM > 250 was affected by the overall effect of other species $(p=0.006$, Table 3$)$, yet, pairwise comparisons within that factor did not show significant effects at the level of $\alpha=$ 0.05 .

Due to the small amounts of surface casts recovered, those samples had to be pooled across experimental blocks, which made it impossible to test for statistically significant treatment effects. When crop residues were surface-applied, SOM content of casts of all earthworm treatments was consistently higher than when crop residues were incorporated. This was particularly noticeable for the POM > 250 (Table 4). However, the amount of casts produced 
was consistently higher when crop residues were incorporated than when crop residues were

313 surface-applied, particularly when L. terrestris was present (Table 4).

\subsection{Water stable aggregates}

315 When residues were surface-applied, both earthworms factors significantly affected aggregate 316 stability at 0 to $20 \mathrm{~cm}$ soil depth: when L. terrestris was present, irrespective of the presence 317 of the other species, a five times increase in WSA > 2000 was observed $(2.71( \pm 0.48)$ vs. $31813.08( \pm 3.31) \mathrm{g} \mathrm{kg}^{-1}$, overall model $\mathrm{p}<0.0001$, Table 5), whereas regardless of the presence 319 of L. terrestris, WSA > 2000 increased almost 2.5 times due to A. caliginosa, and almost 4.5 320 times due to L. rubellus, (pairwise $\mathrm{p}=0.004$ and $\mathrm{p}=0.016$, respectively, Table 5). Also WSA $321250-2000$ were strongly affected by earthworm species, but now also by species combinations 322 (overall model $\mathrm{p}=0.002$, Table 5). When only A. caliginosa was present, significantly less 323 WSA $250-2000$ were found compared to the earthworm-free treatment $(54.14( \pm 2.06)$ vs. $32467.97( \pm 0.67) \mathrm{g} \mathrm{kg}^{-1}$, pairwise $\mathrm{p}<0.0001$, Table 5). In contrast, L. terrestris almost doubled 325 the amount of WSA 250-2000 when present together with L. rubellus $(105.18( \pm 5.94) \mathrm{vs}$. $32667.97( \pm 0.67) \mathrm{g} \mathrm{kg}^{-1}$, pairwise $\mathrm{p}<0.001$, Table 5). In combination with A. caliginosa this 327 increase was about $60 \%$ although not statistically significant different from the earthworm328 free control (pairwise $\mathrm{p}=0.068$, Table 5). Regarding the microaggregates, the combination of 329 L. terrestris with either L. rubellus or A. caliginosa resulted in a $10 \%$ decrease of the WSA $33053-250$ between 0 to $20 \mathrm{~cm}$ soil depth (pairwise $\mathrm{p}=0.003$ and 0.011 , respectively, Table 5 for 331 overall model), and in case of $L$. terrestris combined with A. caliginosa a $7 \%$ decrease in the 332 20-30 cm soil layer was also observed (pairwise $\mathrm{p}=0.026$, Table 5). The silt and clay 333 fractions $(\mathrm{SC}<53)$ in the 0 to $20 \mathrm{~cm}$ soil layer also decreased. Now, the single species 334 treatments with A. caliginosa and L. rubellus decreased SC $<53$ from 130 to $106 \mathrm{~g} \mathrm{~kg}^{-1}$ 335 (pairwise $\mathrm{p}=0.014$ and 0.003 , respectively, Table 5 for overall model). In contrast, at 20 to 
$30 \mathrm{~cm}$ depth, $\mathrm{SC}<53$ was generally increased due to L. terrestris, when present together with either of the other two species, from $119 \mathrm{~g} \mathrm{~kg}^{-1}$ to an average of $158 \mathrm{~g} \mathrm{~kg}^{-1}$ (pairwise $\mathrm{p}=$ 0.002 for LT-AC and 0.033 for LT-LR, Table 5).

When residues were incorporated, L. terrestris together with L. rubellus or A. caliginosa increased WSA 250-2000 at 0 to $20 \mathrm{~cm}$ depth, from about $65 \mathrm{~g} \mathrm{~kg}^{-1}$ in the control treatment to an average of $100 \mathrm{~g} \mathrm{~kg}^{-1}$ (overall model $\mathrm{p}<0.0001$, Table 5, pairwise $\mathrm{p}=0.004$ for LT-AC and 0.049 for LT-LR). In the same soil layer, the combination of L. terrestris with L. rubellus affected WSA 53-250 in the opposite direction, from about 782 in the earthworm-free treatment to $750 \mathrm{~g} \mathrm{~kg}-1$ (overall model $\mathrm{p}<0.0001$, Table 5, pairwise $\mathrm{p}=0.006$ ), while single species, namely A. caliginosa and L. terrestris, resulted in an increase from about 780 to 810 $\mathrm{g} \mathrm{kg}^{-1}$ (pairwise $\mathrm{p}=0.034$ and 0.004 , respectively, Table 5). None of the (single or mixture) species treatment showed significant shifts in WSA 53-250 compared to earthworm-free control treatments at 20 to $30 \mathrm{~cm}$ soil depth, but treatments with L. rubellus and L. terrestris alone had more WSA 53-250 (ca. $\left.790 \mathrm{~g} \mathrm{~kg}^{-1}\right)$ than mixed-species treatments $\left(720 \mathrm{~g} \mathrm{~kg}^{-1}\right)$ (overall model $\mathrm{p}=0.005$, pairwise $\mathrm{p}<0.05$, Table 5). Silt and clay fractions $(\mathrm{SC}<53$ ) were generally lower with single species treatments, when compared to earthworm-free control treatments, at 0 to $20 \mathrm{~cm}$ soil depth (overall model $\mathrm{p}<0.0001$, Table 5 , pairwise $\mathrm{p}=0.001$ for LR, $\mathrm{p}<0.0001$ for AC and LT), whereas at 20 to $30 \mathrm{~cm}$ soil depth, only A. caliginosa showed a decrease in this fraction compared to the earthworm-free control treatment (pairwise $\mathrm{p}=0.010$, Table 5).

\subsection{Soil porosity}

When crop residues were surface-applied, porosity was significantly larger at 2.5 to $10 \mathrm{~cm}$ than between 10 and $35 \mathrm{~cm}$ soil depth, decreasing from $0.8 \%$ of total soil volume to an average of $-0.3 \%$ (overall model $\mathrm{p}=0.006$, Table 6 , Figure $2 \mathrm{~A}$ ). Porosity in the 2.5 to $10 \mathrm{~cm}$ 
soil layer was the only one that was significantly larger than the earthworm-free control treatments $(\mathrm{t}=4.36, \mathrm{p}=0.004)$. The overall effects of earthworm species and of their interactions with soil depth did not significantly affect soil porosity.

When crop residues were incorporated, porosity was larger in 2.5 to 10,10 to 20 and 20 to 30 $\mathrm{cm}$, than in the deepest considered layer, between 30 to $35 \mathrm{~cm}$ soil depth, decreasing from an average of $1 \%$ to $0.3 \%$ (overall model $p=0.011$, pairwise $p<0.05$, Table 6 , Figure $2 B$ ). Species effects on soil porosity were largest in L. terrestris $(1.1 \pm 0.2 \%)$ and larger than in $A$. caliginosa $(0.6 \pm 0.2 \%)$ treatments (overall model $\mathrm{p}=0.025$, pairwise $\mathrm{p}<0.008$, Table 6$)$. In all cases of the incorporated crop residues treatments, porosity was significantly larger than the earthworm-free control treatments $(\mathrm{p}<0.01)$.

\section{Discussion}

\subsection{Response of earthworms to crop residue placement and SOM distribution}

Earthworm survival during the experiment was high, $91 \%$ on average, irrespective of crop residue placement, except for LR when residues were incorporated and LT was present (33\% survival). Besides, in accordance with our first hypothesis, body weight of surface feeders LR and LT was strongly affected by crop residue placement. Incorporating the residues had stronger negative effects on those species, both in treatments with single species (LT or LR) and when both species were present together (LT+LR). The fact that most earthworms lost weight, particularly in mixtures of surface-feeding species (i.e., Lumbricus rubellus and Lumbricus terrestris), is consistent with similar studies in literature in which food was limiting as is common in field conditions under arable farming (Giannopoulos et al., 2010; Rizhiya et al., 2007). The fact that L. rubellus lost significantly more weight in the presence 
of L. terrestris (-47\% and $-79 \%$ when crop residues were surface-applied and incorporated,

384 respectively, Table 1) than when present alone (-0.4\% and $-69 \%$, respectively, Table 1$)$

385 indicates inter-specific competition between both species of the genus Lumbricus, as reported

386 earlier by Uvarov (2009). Lowe and Butt (1999) also observed inter-specific competition

387 among both Lumbricus species when surface organic matter was limiting. In their study, $L$.

388 rubellus constrained the growth of $L$. terrestris, whereas in our study, it was the presence of $L$.

389 terrestris that had a negative effect on L. rubellus. However, it is important to note that Lowe

390 and Butt (1999) started their (three times longer) mesocosm experiments with juvenile

391 individuals. Juveniles of L. terrestris and L. rubellus are much more similar in size, and the

392 fact that we used (sub)adult individuals could have provided an extra competitive advantage

393 to L. terrestris in comparison to L. rubellus. It is worthwhile mentioning that despite some

394 dispute in the literature regarding the ecological grouping of L. rubellus (e.g. Briones and

395 Álvarez-Otero (2018) considered it an epi-anecic and Hendrix et al. (1999) an epigeic or epi-

396 endogeic) our results indicate negative consequences for L. rubellus' survival and body

397 weight when crop residues are incorporated especially so when together with other surface-

398 feeders, in this case with L. terrestris. Although those fitness costs of L. rubellus do not solve

399 the literature dispute, our results indicate that this species should not be grouped within the

400 endogeics.

401 Although we expected facilitation effects between L. terrestris and A. caliginosa, particularly

402 when crop residues were surface-applied, the presence of the former did not show any

403 positive effects on the latter species, nor vice versa. It is worthwhile mentioning that our

404 earthworm performance data is limited to body weight and survival, as we did not measure

405 reproductive output during our experiment. Therefore, we cannot know if e.g. more cocoons

406 were produced by A. caliginosa in the presence of $L$. terrestris, which could be a facilitation

407 effect. Grubert et al. (2016), in contrast to our results, found a body weight gain of $A$. 
caliginosa of about $104 \%$ in the presence of L. terrestris. In temperate arable soils, $A$.

409 caliginosa is the most common earthworm species (Crittenden et al., 2014; Frazão et al.,

410 2017) and it is often assumed that it is stimulated by the incorporation of surface residues by

411 conventional ploughing (Chan, 2001; de Oliveira et al., 2012). Our experimental design aimed

412 at simulating such incorporation of residues, either by manual incorporation or by the activity

413 of L. terrestris. However, A. caliginosa did not benefit from this, as shown by the similar

414 weight change when this species was subjected alone to experimental conditions or when it

415 was combined with L. terrestris, regardless of the crop residue placement (Table 1).

416 Furthermore, irrespective of the presence of A. caliginosa, L. terrestris incorporated POM >

417250 to at least $20 \mathrm{~cm}$ soil depth (Tables 2 and 3), and therefore increased the availability of

418 crop residues for A. caliginosa. We can only speculate about possible reasons for the lack of

419 benefit of A. caliginosa from crop residue incorporation either through tillage or LT, such as

420 the fact that the organic matter could have been possibly too fresh for that species, and/or that

421 the duration of our experiment was too short. On the other hand, it could very well be that the

422 organic matter content (3.7\%) of the soil used was sufficiently high, i.e., not limiting, for $A$.

423 caliginosa.

\section{$424 \quad 4.2$ Earthworm effects on soil structure formation}

\subsubsection{Aggregate stability}

All single earthworm species treatments (LR, AC, and LT) tended to affect WSA similarly,

427 while single species effects were commonly opposite to those of species combinations,

428 irrespective of crop residue placement (Table 5, Figure 3). First, single species always

429 reduced the silt and clay fraction (SC < 53) and increased WSA 53-250 and this effect was

430 most pronounced in under incorporated crop residues for both soil depths (Figure 3B1 and

431 B2), but least pronounced when crop residues were surface-applied and at 20-30 cm depth 
432 (Figure 3A2). Simultaneously, single species treatments never increased macroaggregates

433 (WSA 250-2000 and WSA > 2000) (Figure 3). Second, species combinations always reduced

434 WSA 53-250 (Figure 3). Intriguingly, at 20-30 cm soil depth, this reduction in WSA 53-250

435 was accompanied particularly by an increase in the silt and clay fraction $(\mathrm{SC}<53)$,

436 irrespective of crop residue placement (Figure 3A2 and B2). However, at 0-20 cm soil depth

437 the decrease in WSA 53-250 coincided with an increase in water-stable macroaggregates,

438 both WSA 250-2000 and WSA > 2000 when crop residues were surface-applied (Figure

439 3A1), or only WSA 250-2000 when crop residues were incorporated (Figure 3B1). It seems,

440 therefore, that single species treatments have a stabilizing effect at the microaggregate level,

441 whereas combinations of functional groups are more effective in formation and stabilization

442 of macroaggregates.

443 The observed patterns may, however, reflect different ecological mechanisms caused by the

444 species combinations applied. We argue the data indicate competition between LT and LR

445 due to food shortage in the surface-applied crop residue treatments, as a result of more

446 individuals within the same feeding guild, i.e. surface-feeders. The food shortage could imply

447 that surface feeders needed to be more active while searching for food which could have

448 resulted in a larger proportion of water-stable macroaggregates, due to larger amounts of

449 ingested soil. This claim is supported by our earthworm performance data (see section 4.1 and

450 Table 1), where competition between both surface feeders was demonstrated, since LR lost

451 more weight when together with LT then when alone. In the case of incorporated crop

452 residues the earthworm performance data did not support facilitation between LT and AC (see

453 section 4.1 and Table 1). However, our data suggests complementarity between those species

454 in terms of soil structure formation, as macroaggregates increased in the presence of LT and

455 AC, at least in the upper $20 \mathrm{~cm}$ soil depth. 
456 Our results oppose those found by Bossuyt et al. (2006), Fonte et al. (2007) and Giannopoulos 457 et al. (2010), and, in turn, those studies also showed contrasting results among themselves.

458 Fonte et al. (2007) did not find any effects of earthworms on any aggregate size fraction, 459 whereas Giannopoulos et al. (2010) only found a weak significant increase in water-stable 460 macroaggregates, from $27 \%$ to $32 \%$, with A. caliginosa, when residues were incorporated. 461 Bossuyt et al. (2006) demonstrated that large water-stable aggregates increased with all 462 earthworm treatments when crop residues were surface-applied and incorporated in the soil. 463 In the case of Fonte et al. (2007), intact soil cores were used, whereas we repacked soil 464 columns. As for Giannopoulos et al. (2010) who also used repacked columns, their soil pre465 treatment involved sieving through $8 \mathrm{~mm}$, whereas we used a 4-mm mesh-size. Consequently, 466 in our study, soil structure was "re-set" due to the soil sieving prior to the experiment's 467 establishment, which could have accounted for the different experimental outcomes. The soil 468 pre-treatment applied by Bossuyt et al. (2006) completely "re-set" initial soil structure, as 469 they sieved their soil through $250 \mu \mathrm{m}$. After correcting for the experimental duration, 470 earthworm density and soil volume used, their rate of WSA > 2000 formation was between 3 471 and 5 times larger than ours in the case of surface-applied residues and between 20 and 70 472 times larger when residues were incorporated, depending on whether earthworm treatments 473 consisted of single or two species. Caro et al. (2012) demonstrated that increasing intra474 specific density increased the mobility of several earthworm species, and therefore their 475 activity. Speculatively, we consider that the results of Bossuyt et al. (2006), who used six 476 earthworms in $500 \mathrm{~g}$ of soil (whereas we used a maximum of 0.3 earthworm per $500 \mathrm{~g}$ of 477 soil), could also be a product of the unrealistically high earthworm density used.

479 Our experiment revealed that crop residue placement may induce some plasticity in 480 earthworm burrowing behaviour, due to the necessity of earthworms to find food. In a field 
481

482

483

484

485

study in Normandy, Pérès et al. (2010) discussed the possibility that low organic matter availability in maize arable fields would increase the number of burrows made by earthworms as a result of their search for food. Our results are in line with this explanation as we observed an increase of earthworm-mediated soil porosity with soil depth, when crop residues were incorporated in the soil profile (Figure 2B). In contrast, when crop residues were surfaceapplied, earthworms restricted their burrowing activity up to $10 \mathrm{~cm}$ soil depth (Figure $2 \mathrm{~A}$ ). However, it seems that the burrowing plasticity brings a trade-off, as especially L. rubellus lost much more weight when crop residues were incorporated (average of $69 \%$ body weight loss) than when those were surface-applied ( $0.4 \%$ of body weight loss). To our knowledge, only one study has focused on earthworm burrowing patterns in relation to location of food (Le Couteulx et al., 2015), but it was restricted to endogeic species. It remains therefore difficult to compare our results with current available literature. Furthermore, our findings regarding A. caliginosa contrasted those of Le Couteulx et al. (2015), especially when crop residues were surface-applied. In their study, A. caliginosa was shown to increase porosity twice as much when food was mixed throughout the soil profile (approximately $0.68 \%$ porosity in the upper $10 \mathrm{~cm}$ soil depth) than when it was scattered at the soil surface $(0.34 \%)$. In our study however, porosity made by $A$. caliginosa in the upper $10 \mathrm{~cm}$ of soil depth, was approximately $0.79 \%$ when residues were incorporated $v s .0 .93 \%$ when residues were surface-applied (data not shown, as it was NS). Although species-mediated porosity was not significant when crop residues were surface-applied, our results suggest that indeed there is an increase of porosity when food is more limiting. Nevertheless, it is worthwhile mentioning that given the fact that the soil used by Le Couteulx et al. (2015) had a much lower organic matter content than ours ( $2 \%$ vs $3.7 \%$ ), one would have expected a higher porosity with their experimental conditions, which was not the case.

\subsection{Implications for field conditions}


By incorporating crop residues at ploughing depth, we did not simulate the mouldboard

507 ploughing activity in itself, but one of its consequences, i.e. the displacement of food that 508 would have been available for surface-feeders. In fact, the "real" consequences of ploughing

509 could be even more severe due to the destruction of earthworm burrows and increase in

510 mortality (Chan, 2001), e.g. due to predation. Our results regarding soil structure suggest that

511 large water stable macroaggregates could be reduced through the incorporation of crop

512 residues as compared to surface application. Porosity, however, was stimulated by residue 513 incorporation, at least in single species treatments and within the time frame of 61 days, with

514 the strongest effects for L. terrestris. Our data revealed some plasticity in burrowing activities 515 in response to crop residue placement, at least for L. rubellus. A. caliginosa did not have large 516 effects on soil porosity, stable aggregation or SOM distribution, nor was its population 517 density or biomass affected by crop residue placement. Non-inversion, or minimum tillage 518 practices, by providing crop residues at the soil surface seems to improve the fitness of 519 earthworm species that feed at the soil surface with negligible effects on endogeic species, 520 and contributes to improved soil structure due to an increase of water-stable macroaggregates 521 in the upper $20 \mathrm{~cm}$ soil. Furthermore, the combination of anecics (L. terrestris) with the other 522 earthworm functional groups also contributes to improving soil structure, due to the increase 523 of large and small macroaggregates.

\section{Conclusions}

526 We demonstrated that providing crop residues on the soil surface or incorporating them in the 527 soil profile affects earthworm performance, crop residue distribution, soil porosity and 528 aggregate stability. Because of the importance of soil structure maintenance for sustainable 529 land use, and the key role of earthworms belonging to different functional groups in 530 mediating these soil processes, farmers should give careful thought when taking decisions 
531 about their crop residue management practices. Those decisions should improve food supply

532 for earthworms belonging to different functional groups.

\section{Acknowledgements}

536 We are thankful to Naira Cuareli de Moura and Lur Moragues Saitua for processing soil 537 samples to obtain the WSA data, to Jaap Nelemans, Willeke van Tintelen and Gwénaëlle 538 Flageul for processing soil samples to obtain the SOM data, to Remco Hamoen for helping

539 with the X-ray tomography, to Tamas Salanki and Esperanza Huerta for help in collecting 540 earthworms and to the late Arie Brader for help in filling the columns. This work was 541 supported by the Netherlands Organisation for Scientific Research (NWO) and is part of the 542 research programme Biodiversiteit Werkt! with project number 841.11.003.

\section{References}

545 Andriuzzi, W.S., Pulleman, M.M., Schmidt, O., Faber, J.H., Brussaard, L., 2015. Anecic earthworms (Lumbricus terrestris) alleviate negative effects of extreme rainfall events on soil and plants in field mesocosms. Plant Soil 397(1-2), 103-113.

Bossuyt, H., Six, J., Hendrix, P.F., 2006. Interactive effects of functionally different earthworm species on aggregation and incorporation and decomposition of newly added residue carbon. Geoderma 130(1-2), 14-25.

551 Bouché, M.B., 1977. Strategies lombriciennes. Ecological Bulletins 25, 122-132.

552 Briones, M.J.I., Álvarez-Otero, R., 2018. Body wall thickness as a potential functional trait for assigning earthworm species to ecological categories. Pedobiologia 67, 26-34. 
Capowiez, Y., Bottinelli, N., Sammartino, S., Michel, E., Jouquet, P., 2015. Morphological and functional characterisation of the burrow systems of six earthworm species (Lumbricidae). Biology and Fertility of Soils 51(7), 869-877.

Capowiez, Y., Monestiez, P., Belzunces, L., 2001. Burrow systems made by Aporrectodea nocturna and Allolobophora chlorotica in artificial cores: morphological differences and effects of interspecific interactions. Applied Soil Ecology 16(2), 109-120.

Caro, G., Abourachid, A., Decaëns, T., Buono, L., Mathieu, J., 2012. Is earthworms' dispersal facilitated by the ecosystem engineering activities of conspecifics? Biology and Fertility of Soils 48, 961-965.

Chan, K.Y., 2001. An overview of some tillage impacts on earthworm population abundance and diversity — implications for functioning in soils. Soil \& Tillage Research 57(4), 179-191.

Coq, S., Barthès, B.G., Oliver, R., Rabary, B., Blanchart, E., 2007. Earthworm activity affects soil aggregation and organic matter dynamics according to the quality and localization of crop residues_-An experimental study (Madagascar). Soil Biology and Biochemistry 39(8), 2119-2128.

Crittenden, S.J., Eswaramurthy, T., de Goede, R.G.M., Brussaard, L., Pulleman, M.M., 2014. Effect of tillage on earthworms over short- and medium-term in conventional and organic farming. Applied Soil Ecology 83, 140-148.

Crittenden, S.J., Huerta, E., de Goede, R.G.M., Pulleman, M.M., 2015. Earthworm assemblages as affected by field margin strips and tillage intensity: An on-farm approach. European Journal of Soil Biology 66(0), 49-56.

Cuendet, G., 1983. Predation on earthworms by the black-headed gull (Larus ridibundus L.). In: J.E. Satchell (Ed.), Earthworm Ecology: From Darwin to Vermiculture. Springer Netherlands, Dordrecht, pp. 415-424. 
de Bakker, H., Schelling, J., 1966. Systeem van bodemclassificatie voor Nederland: de hogere niveaus. Centrum voor Landbouwpublikaties en Landbouwdocumentatie, Wageningen.

de Oliveira, T., Bertrand, M., Roger-Estrade, J., 2012. Short-term effects of ploughing on the abundance and dynamics of two endogeic earthworm species in organic cropping systems in northern France. Soil \& Tillage Research 119, 76-84.

Elliott, E.T., 1986. Aggregate structure and Carbon, Nitrogen, and Phosphorus in native and cultivated soils. Soil Science Society of America Journal 50(3), 627-633.

Ernst, G., Emmerling, C., 2009. Impact of five different tillage systems on soil organic carbon content and the density, biomass, and community composition of earthworms after a ten year period. European Journal of Soil Biology 45(3), 247-251.

Fonte, S.J., Kong, A.Y.Y., van Kessel, C., Hendrix, P.F., Six, J., 2007. Influence of earthworm activity on aggregate-associated carbon and nitrogen dynamics differs with agroecosystem management. Soil Biology and Biochemistry 39(5), 1014-1022.

Frazão, J., de Goede, R.G.M., Brussaard, L., Faber, J.H., Groot, J.C.J., Pulleman, M.M., 2017. Earthworm communities in arable fields and restored field margins, as related to management practices and surrounding landscape diversity. Agriculture, Ecosystems \& Environment 248, 1-8.

Giannopoulos, G., Pulleman, M.M., Van Groenigen, J.W., 2010. Interactions between residue placement and earthworm ecological strategy affect aggregate turnover and N2O dynamics in agricultural soil. Soil Biology and Biochemistry 42(4), 618-625.

Grubert, D., Butenschoen, O., Maraun, M., Scheu, S., 2016. Understanding earthworm Collembola interactions and their importance for ecosystem processes needs consideration of species identity. European Journal of Soil Biology 77, 60-67. 
Hedde, M., Bureau, F., Delporte, P., Cécillon, L., Decaëns, T., 2013. The effects of earthworm species on soil behaviour depend on land use. Soil Biology and Biochemistry 65, 264-273.

Hendrix, P.F., Callaham Jr, M.A., Lachnicht, S.L., Blair, J.M., James, S.W., Zou, X., 1999. Stable isotopic studies of resource utilization by nearctic earthworms (Diplocardia, Oligochaeta) in subtropical savanna and forest ecosystems. Pedobiologia 43(6), 818823.

Jones, C.G., Lawton, J.H., Shachak, M., 1994. Organisms as Ecosystem Engineers. Oikos 69(3), 373-386.

Lavelle, P., Bignell, D., Lepage, M., Wolters, V., Roger, P., Ineson, P., Heal, O., Dhillion, S., 1997. Soil function in a changing world: the role of invertebrate ecosystem engineers. European Journal of Soil Biology 33(4), 159-193.

Le Couteulx, A., Wolf, C., Hallaire, V., Pérès, G., 2015. Burrowing and casting activities of three endogeic earthworm species affected by organic matter location. Pedobiologia 58(2-3), 97-103.

Lemtiri, A., Colinet, G., Alabi, T., Cluzeau, D., Zirbes, L., Haubruge, É., Francis, F., 2014. Impacts of earthworms on soil components and dynamics. A review. Biotechnologie, Agronomie, Société et Environnement= Biotechnology, Agronomy, Society and Environment [= BASE $] 18$.

Lowe, C.N., Butt, K.R., 1999. Interspecific interactions between earthworms: A laboratorybased investigation. Pedobiologia 43(6), 808-817.

Lowe, C.N., Butt, K.R., 2002. Growth of hatchling earthworms in the presence of adults: interactions in laboratory culture. Biology and Fertility of Soils 35(3), 204-209.

Lowe, C.N., Butt, K.R., 2003. Influence of food particle size on inter- and intra-specific interactions of Allolobophora chlorotica (Savigny) and Lumbricus terrestris: The 7th 
international symposium on earthworm ecology · Cardiff · Wales $\cdot 2002$. Pedobiologia 47(5-6), 574-577.

Lubbers, I.M., van Groenigen, J.W., 2013. A simple and effective method to keep earthworms confined to open-top mesocosms. Applied Soil Ecology 64, 190-193.

Martin, N.A., 1982. The interaction between organic-matter in soil and the burrowing activity of 3 species of earthworms (Oligochaeta, Lumbricidae). Pedobiologia 24(4), 185-190.

Paul, B.K., Lubbers, I.M., van Groenigen, J.W., 2012. Residue incorporation depth is a controlling factor of earthworm-induced nitrous oxide emissions. Global Change Biology 18(3), 1141-1151.

Pérès, G., Bellido, A., Curmi, P., Marmonier, P., Cluzeau, D., 2010. Relationships between earthworm communities and burrow numbers under different land use systems. Pedobiologia 54(1), 37-44.

Petersen, H., Luxton, M., 1982. A comparative analysis of soil fauna populations and their role in decomposition processes. Oikos 39(3), 288-388.

Pulleman, M., Jongmans, A., Marinissen, J., Bouma, J., 2003. Effects of organic versus conventional arable farming on soil structure and organic matter dynamics in a marine

R Core Team, 2014. R: A language and environment for statistical computing. R Foundation for Statistical Computing, Vienna, Austria.

Rizhiya, E., Bertora, C., van Vliet, P.C.J., Kuikman, P.J., Faber, J.H., van Groenigen, J.W., 2007. Earthworm activity as a determinant for N2O emission from crop residue. Soil Biology and Biochemistry 39(8), 2058-2069. Paustian, K., 2002. Measuring and understanding Carbon storage in afforested soils by physical fractionation. Soil Science Society of America Journal 66(6), 1981-1987. 
653 Syers, J.K., Springett, J.A., 1984. Earthworms and soil fertility. Plant Soil 76(1), 93-104.

654 Uvarov, A.V., 2009. Inter- and intraspecific interactions in lumbricid earthworms: Their role for earthworm performance and ecosystem functioning. Pedobiologia 53(1), 1-27.

656 van Groenigen, J.W., Lubbers, I.M., Vos, H.M.J., Brown, G.G., de Deyn, G.B., van Groenigen, K.J., 2014. Earthworms increase plant production: a meta-analysis. 4, 6365.

659

Zuur, A., Ieno, E.N., Walker, N., Saveliev, A.A., Smith, G.M., 2009. Mixed effects models

660 and extensions in ecology with R. Springer, New York.

661

662 Tables

663 Table 1 - Percentage of body weight change (from the initial body weight) and of survival

664 (mean (SE)) of earthworms used in each of the experimental treatments (crop residue

665 treatments: surface-applied $v s$. incorporated at 20-30 cm soil depth; and earthworm

666 treatments: L. terrestris - present (LT) or absent; other species - none, A. caliginosa (AC), or

667 L. rubellus (LR)), after 61 days. F-statistics and p-values of best fitted linear mixed model of

668 earthworm body weight change (\% of initial body weight) and survival. $\mathrm{N}=4$, but see *.
L. terrestris (LT)
L. rubellus (LR)
A. caliginosa (AC)

Treatment

$\begin{array}{rrrrrr}\text { Weight } & \text { Survival } & \text { Weight } & \text { Survival } & \text { Weight } & \text { Survival } \\ \text { change }(\%) & (\%) & \text { change }(\%) & (\%) & \text { change }(\%) & (\%)\end{array}$

\section{Surface applied crop residues}

$\mathrm{AC}$

$\begin{array}{rrrr}- & - & -18.9(17.0) & 81.3(12.0) \\ -0.4(8.0) & 100(0.0) & - & - \\ - & - & - & \\ - & - & -20.8(9.1) & 100.0(0.0)\end{array}$

$\mathbf{L T}+\mathbf{A C}$

$-0.8(4.9) \quad 100.0(0.0)$

$-20.8(9.1)$ 
$\mathbf{L T + L R} \quad-13.4(2.1) \quad 100.0(0.0) \quad-46.7(4.3) \quad 83.4(9.6)$

\section{Crop residues incorporated at $20-30 \mathrm{~cm}$ soil depth}

$\mathrm{AC}$

$-28.7(6.7)$

$87.5(7.2)$

LR

$\begin{array}{lll}- & -68.7(19.9)^{*} \quad 66.7(23.6)\end{array}$

LT

$-28.2(3.1) \quad 100.0(0.0)$

$\mathbf{L T}+\mathrm{AC}$

$-35.8(6.7) \quad 91.7(8.3)$

$-29.3(4.0)$

$93.8(6.3)$

$\mathbf{L T}+\mathbf{L R}$

$-27.1(13.8)$

$91.7(8.3)$

$-79.0(15.3)$

$33.3(23.6)$

\section{Mixed models (F and p-values)}

$\begin{array}{llllllllllll}\mathbf{F} & \mathbf{p} & \mathbf{F} * * & \mathbf{P} * * & \mathbf{F} & \mathbf{p} & \mathbf{F} & \mathbf{p} & \mathbf{F} & \mathbf{p} & \mathbf{F} & \mathbf{p}\end{array}$

$\begin{array}{lllllllllllll}\text { Placement } & 48.27 & \underline{\mathbf{5 0 . 0 0 0 1}} & \text { NA } & \text { NA } & 17.14 & \underline{\mathbf{0 . 0 0 3}} & 5.81 & \underline{\mathbf{0 . 0 3 9}} & 1.01 & 0.342 & 0.53 & 0.484\end{array}$

$\begin{array}{llllllllllllll}\text { L. terrestris } & - & & - & \text { NA } & \text { NA } & 28.37 & \underline{\mathbf{0 . 0 0 1}} & 3.85 & 0.081 & 0.01 & 0.920 & 2.67 & 0.137\end{array}$

Other species $\quad 0.12 \quad 0.889 \quad$ NA $\quad$ NA

Placement x

L. terrestris

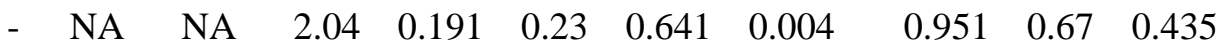

Placement $x$

Other species

$2.52 \quad 0.114 \quad$ NA $\quad$ NA

669

$670 *$ In one of the blocks all L. rubellus died during the gut voiding-period, thus value refers to $\mathrm{n}$

$671=3$. 
$672 * *$ Variation in survival was very low, and therefore statistics are not available (NA).

673 
674 Table 2 - Mean and standard errors of soil organic matter (SOM) size fractions in $\mathrm{g} \mathrm{kg}^{-1}$ soil

$675(\mathrm{POM}>250 \mu \mathrm{m}, \mathrm{POM} 53-250 \mu \mathrm{m}$, and $\mathrm{SOM}<53 \mu \mathrm{m})$ of surface-applied crop residues

676 per soil depth $(0-20,20-30$ and $>30 \mathrm{~cm})$ after 61 days as affected by different earthworm

677 species and their combinations. No earthworms: 0, L. terrestris-LT, A. caliginosa-AC, $L$.

678 rubellus-LR. F-statistics and p-values of best fitted linear mixed model of SOM size fractions.

679 Different letters depict pairwise significant differences at $\mathrm{p}<0.05$ : capital letters show

680 significant differences within the main factor L. terrestris, and small letters within the main

681 factor Other species. $\mathrm{N}=4$.

\section{SOM fraction}

/earthworm

\section{Soil depth}

treatment

\begin{tabular}{rrrr}
\hline & $\mathbf{0 - 2 0} \mathbf{~ c m}$ & $\mathbf{2 0 - 3 0 ~ c m}$ & $>30 \mathbf{~ c m}$ \\
\hline $\mathbf{P O M}>\mathbf{2 5 0} \boldsymbol{\mu \mathbf { m }}$ & & & \\
$\mathbf{A C}$ & $1.08(0.05) \mathrm{Aa}$ & $1.00(0.03)$ & $1.09(0.06)$ \\
$\mathbf{L R}$ & $1.20(0.05) \mathrm{Aa}$ & $0.99(0.05)$ & $1.03(0.08)$ \\
$\mathbf{L T}$ & $1.30(0.09) \mathrm{Ba}$ & $1.00(0.04)$ & $1.02(0.02)$ \\
$\mathbf{L T}+\mathbf{A C}$ & $1.32(0.11) \mathrm{Ba}$ & $1.08(0.06)$ & $1.07(0.06)$ \\
$\mathbf{L T}+\mathbf{L R}$ & $1.19(0.10) \mathrm{Ba}$ & $0.96(0.03)$ & $1.00(0.02)$
\end{tabular}

POM 53-250 $\mu \mathrm{m}$

$\begin{array}{cccc}\text { 0 } & 3.11(0.24) & 2.57(0.08) \mathrm{Aa} & 2.60(0.14) \\ \text { AC } & 3.06(0.09) & 2.75(0.50) \mathrm{Aab} & 2.96(0.50) \\ \text { LR } & 2.82(0.22) & 3.04(0.27) \mathrm{Ab} & 2.72(0.27) \\ \text { LT } & 3.12(0.09) & 2.52(0.21) \mathrm{Aa} & 3.05(0.21)\end{array}$




$\begin{array}{llll}\mathbf{L T}+\mathbf{A C} & 2.98(0.31) & 2.77(0.18) \mathrm{Aab} & 2.89(0.18) \\ \mathbf{L T + L R} & 3.52(0.08) & 3.36(0.23) \mathrm{Ab} & 2.70(0.23)\end{array}$

$\mathrm{SOM}<53 \mu \mathrm{m}$

$\begin{array}{rccc}\mathbf{0} & 33.97(1.40) & 32.93(0.84) \mathrm{Ba} & 32.60(0.98) \\ \mathbf{A C} & 32.09(0.75) & 35.11(1.61) \mathrm{Ba} & 32.02(0.85) \\ \mathbf{L R} & 34.79(0.64) & 34.02(0.44) \mathrm{Ba} & 33.80(0.69) \\ \mathbf{L T} & 32.94(0.70) & 32.51(0.14) \mathrm{Aa} & 34.15(0.98) \\ \mathbf{\text { TT+AC }} & 33.82(1.11) & 32.84(0.45) \mathrm{Aa} & 32.11(1.22) \\ \mathbf{\text { TT+LR }} & 33.33(0.74) & 31.63(1.01) \mathrm{Aa} & 32.97(1.35)\end{array}$

Mixed models (F and p-values)

\begin{tabular}{rrrrrrr} 
& $\mathbf{F}$ & $\mathbf{p}$ & $\mathbf{F}$ & $\mathbf{p}$ & $\mathbf{F}$ & $\mathbf{p}$ \\
\hline POM $>$ 250 $\boldsymbol{\mu m}$ & & & & & & \\
L. terrestris & 7.73 & $\underline{\mathbf{0 . 0 1 4}}$ & 0.27 & 0.613 & 0.16 & 0.700 \\
Other species & 3.45 & 0.059 & 1.03 & 0.380 & 1.36 & 0.287 \\
$\begin{array}{r}\text { L. terrestris x Other } \\
\text { species }\end{array}$ & 2.18 & 0.148 & 0.67 & 0.528 & 0.03 & 0.974
\end{tabular}

POM 53-250 $\mu \mathrm{m}$

$\begin{array}{rcccccc}\text { L. terrestris } & 1.71 & 0.211 & 0.31 & 0.587 & 1.45 & 0.247 \\ \text { Other species } & 0.29 & 0.749 & 7.69 & \underline{\mathbf{0 . 0 0 5}} & 0.29 & 0.754 \\ \begin{array}{r}\text { L.terrestris x Other } \\ \text { species }\end{array} & 2.39 & 0.126 & 0.38 & 0.688 & 0.84 & 0.451\end{array}$

SOM $<53 \mu \mathrm{m}$ 
$\begin{array}{lllllll}\text { L. terrestris } & 0.11 & 0.741 & 10.90 & \underline{\mathbf{0 . 0 0 5}} & 0.17 & 0.685\end{array}$

$\begin{array}{lllllll}\text { Other species } & 0.71 & 0.508 & 0.42 & 0.663 & 1.84 & 0.192\end{array}$

L. terrestris $\mathrm{x}$ Other

$\begin{array}{lllllll}\text { species } & 1.73 & 0.212 & 1.19 & 0.331 & 1.15 & 0.344\end{array}$

682 
683 Table 3 - Mean and standard errors of soil organic matter (SOM) size fractions in $\mathrm{g} \mathrm{kg}^{-1}$ soil $684(\mathrm{POM}>250 \mu \mathrm{m}, \mathrm{POM} 53-250 \mu \mathrm{m}$, and $\mathrm{SOM}<53 \mu \mathrm{m})$ of incorporated crop residues per 685 soil depth $(0-20,20-30$ and $>30 \mathrm{~cm})$ after 61 days as affected by different earthworm species 686 and their combinations. No earthworms: 0, L. terrestris-LT, A. caliginosa-AC, L. rubellus687 LR. F-statistics and p-values of best fitted linear mixed model of SOM size fractions. 688 Different letters depict pairwise significant differences at $\mathrm{p}<0.05$ : capital letters show 689 significant differences within the main factor L. terrestris, and small letters within the main 690 factor Other species. $\mathrm{N}=4$.

\begin{tabular}{|c|c|c|c|}
\hline \multirow{2}{*}{$\begin{array}{c}\text { SOM } \\
\text { fraction/earthworm } \\
\text { treatment }\end{array}$} & \multicolumn{3}{|c|}{ Soil depth } \\
\hline & $0-20 \mathrm{~cm}$ & $20-30 \mathrm{~cm}$ & $>30 \mathrm{~cm}$ \\
\hline \multicolumn{4}{|l|}{$\mathrm{POM}>250 \mu \mathrm{m}$} \\
\hline $\mathbf{0}$ & $1.01(0.02) \mathrm{Aa}$ & $2.78(0.13)$ & $1.18(0.06)$ \\
\hline AC & $0.99(0.02) \mathrm{Aa}$ & $2.51(0.07)$ & $1.08(0.07)$ \\
\hline LR & $0.96(0.03) \mathrm{Aa}$ & $3.13(0.12)$ & $1.26(0.14)$ \\
\hline LT & $1.08(0.08) \mathrm{Ba}$ & $2.96(0.40)$ & $1.12(0.06)$ \\
\hline $\mathbf{L T}+\mathbf{A C}$ & $1.05(0.05) \mathrm{Ba}$ & $2.59(0.17)$ & $1.19(0.04)$ \\
\hline $\mathbf{L T}+\mathbf{L R}$ & $1.06(0.07) \mathrm{Ba}$ & $2.79(0.22)$ & $1.19(0.07)$ \\
\hline
\end{tabular}

\section{POM 53-250 $\mu \mathrm{m}$}

0

AC

LR

LT
$2.69(0.15)$

$2.87(0.25)$

$2.66(0.18)$

$3.02(0.11)$
$2.66(0.26)$

$2.93(0.17)$

$3.27(0.27)$

$2.45(0.23)$

$2.95(0.27)$

$2.91(0.09)$

$2.78(0.59)$

$3.03(0.14)$ 

$\mathbf{L T}+\mathbf{A C}$
$2.75(0.17)$
$3.29(0.45)$
$3.02(0.63)$
LT+LR
$2.89(0.21)$
$2.96(0.22)$
$2.94(0.23)$

\section{SOM $<53 \mu \mathrm{m}$}

$\begin{array}{llll}\mathbf{0} & 34.67(2.16) & 33.88(0.67) & 35.18(1.14) \\ \mathbf{A C} & 32.95(0.90) & 35.17(0.92) & 35.11(0.70) \\ \mathbf{L R} & 32.73(1.31) & 33.27(0.51) & 32.35(1.33) \\ \mathbf{L T} & 33.07(1.41) & 34.04(1.84) & 34.31(0.84) \\ \mathbf{L T + A C} & 33.22(1.32) & 33.92(0.51) & 33.51(0.81) \\ \mathbf{L T + L R} & 35.87(0.76) & 34.55(1.17) & 35.71(1.28)\end{array}$

Mixed models (F and p-values)

\begin{tabular}{|c|c|c|c|c|c|c|}
\hline & $\mathbf{F}$ & $\mathbf{p}$ & $\mathbf{F}$ & $\mathbf{p}$ & $\mathbf{F}$ & $\mathbf{p}$ \\
\hline \multicolumn{7}{|l|}{$\mathrm{POM}>250 \mu \mathrm{m}$} \\
\hline L. terrestris & 4.92 & $\underline{0.043}$ & 0.03 & 0.875 & 0.01 & 0.913 \\
\hline Other species & 1.23 & 0.313 & 7.42 & $\underline{0.006}$ & 3.43 & 0.060 \\
\hline $\begin{array}{l}\text { L. terrestris x Other } \\
\text { species }\end{array}$ & 0.13 & 0.879 & 0.84 & 0.451 & 1.42 & 0.272 \\
\hline
\end{tabular}

POM 53-250 $\mu \mathrm{m}$

$\begin{array}{lcccccc}\text { L. terrestris } & 2.44 & 0.139 & 0.01 & 0.923 & 3.91 & 0.067 \\ \text { Other species } & 0.13 & 0.881 & 1.16 & 0.340 & 1.58 & 0.239 \\ \begin{array}{l}\text { L. terrestris x Other } \\ \text { species }\end{array} & 0.78 & 0.476 & 0.01 & 0.990 & 0.27 & 0.769\end{array}$

$\mathrm{SOM}<53 \mu \mathrm{m}$ 
L. terrestris

Other species

L. terrestris $\mathrm{x}$ Other species
$0.29 \quad 0.601$

$0.40 \quad 0.678$

$1.49 \quad 0.258$
4.42

0.053

0.43

0.523

1.15

0.343

$0.21 \quad 0.810$

691 
692 Table 4-SOM fractions ( $\mathrm{g} \mathrm{kg}^{-1}$ cast) and weight of the pooled amount of the surface casts $(\mathrm{g})$

693 after 61 days, as affected by different earthworm species and their combinations when crop

694 residues were placed at the soil surface or incorporated in the soil profile. No earthworms: 0,

695 L. terrestris-LT, A. caliginosa-AC, L. rubellus-LR. Only means are available because casts

696 were pooled among the four different blocks due to scarcity of cast material.

\begin{tabular}{lrrrr}
\hline \multicolumn{1}{c}{ Treatment } & \multicolumn{2}{c}{ SOM size fractions } & \multicolumn{2}{c}{$\begin{array}{c}\text { Weight of casts } \\
\text { produced (g) }\end{array}$} \\
\hline Surface applied crop residues & & & \\
AC & 3.84 & 3.54 & 36.93 & 45.8 \\
LR & 22.24 & 8.52 & 47.58 & 110.7 \\
LT & 15.31 & 3.65 & 40.94 & 190.2 \\
LT+AC & 14.34 & 4.17 & 36.93 & 135.6 \\
LT+LR & 12.71 & 3.41 & 38.39 & 267.0
\end{tabular}

Crop residues incorporated at $20-30 \mathrm{~cm}$ soil depth

\begin{tabular}{llllr}
$\mathbf{A C}$ & 0.99 & 3.33 & 33.10 & 26.2 \\
$\mathbf{L R}$ & 1.18 & 2.69 & 32.63 & 35.6 \\
$\mathbf{L T}$ & 2.27 & 2.57 & 28.17 & 358.5 \\
$\mathbf{L T + A C}$ & 1.16 & 3.66 & 33.93 & 366.2 \\
$\mathbf{L T + L R}$ & 1.74 & 2.50 & 33.90 & 456.0 \\
\hline
\end{tabular}

697 
698 Table 5 - Mean amounts and standard errors of water-stable aggregate (WSA) size fractions

699 in $\mathrm{g} \mathrm{kg}^{-1}$ soil (WSA > $2000 \mu \mathrm{m}$, WSA 250-2000 $\mu \mathrm{m}$, WSA 53-250 $\mu \mathrm{m}$, and silt and clay SC <

$70053 \mu \mathrm{m})$ of surface-applied and incorporated crop residues per soil depth $(0-20$ and $20-30 \mathrm{~cm})$

701 after 61 days as affected by different earthworm species and their combinations. No

702 earthworms: 0, L. terrestris-LT, A. caliginosa-AC, L. rubellus-LR. F-statistics and p-values of

703 best fitted linear mixed model of WSA size fractions. Different letters depict pairwise

704 significant differences at $\mathrm{p}<0.05$ : capital letters show significant differences within the main

705 factor L. terrestris, and small letters within the main factor Other species. When only small

706 letters are provided, significant differences refer to the interaction between both earthworm

707 treatments. $\mathrm{N}=4$.

\section{WSA size}

class/earthworm

Crop residue treatment and soil depth

treatment

Surface applied crop residues

0-20 cm

20-30 cm

WSA > $2000 \mu \mathrm{m}$ (large macroaggregates)

0

AC

LR

LT

$\mathbf{L T}+\mathrm{AC}$

$\mathbf{L T}+\mathbf{L R}$

$23.31(7.58) \mathrm{Bb}$

$1.18(0.15) \mathrm{Aa}$

$1.95(0.34)$

$1.67(0.32)$

$0.87(0.47)$

$1.00(0.27)$

$5.33(3.76)$

$3.86(1.82)$

$3.62(1.59)$

$1.31(0.68)$

$1.89(1.20)$

$1.23(0.78)$

$1.89(0.34)$

$1.07(0.53)$

WSA 250 - $2000 \mu \mathrm{m}$ (small macroaggregates)

0

$73.01(6.36)$

$65.37(4.82) \mathrm{a}$

11.17 (1.87)

13.27 (1.47)

12.24 (2.09)

$11.01(2.89)$

18.69 (5.18)

$12.05(2.26)$

$67.97(0.67) b$

$$
67.97(0.67) \mathrm{b}
$$

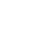




$\begin{array}{lrrrr}\text { AC } & 54.14(2.06) \mathrm{a} & 70.53(8.01) & 59.05(6.55) \mathrm{a} & 87.94(14.70) \\ \mathbf{L R} & 64.28(9.22) \mathrm{ab} & 89.65(18.43) & 59.45(5.35) \mathrm{a} & 80.24(5.91) \\ \mathbf{L T} & 62.73(7.79) \mathrm{ab} & 63.16(10.95) & 57.82(1.70) \mathrm{a} & 68.01(8.61) \\ \mathbf{L T + A C} & 88.42(8.38) \mathrm{bc} & 78.73(7.16) & 109.88(9.04) \mathrm{b} & 116.86(19.47) \\ \mathbf{L T + L R} & 105.18(5.94) \mathrm{c} & 75.11(4.65) & 94.38(7.52) \mathrm{b} & 101.79(10.81)\end{array}$

\section{WSA 53 - $250 \mu \mathrm{m}$ (microaggregates)}

0

AC

LR

LT

$\mathbf{L T}+\mathbf{A C}$

LT+LR
$788.12(3.03) \mathrm{b}$

$809.33(2.84) b$

$808.34(10.53) b$

$797.16(10.04) b$

$736.61(16.66) \mathrm{a}$

$728.35(10.31) \mathrm{a}$
$790.21(8.96) b c$

$799.07(6.64) \mathrm{c}$

$770.64(27.62) a b c$

$809.79(6.50)$ c

$744.74(4.91) \mathrm{a}$

$760.6(8.18) a b$
782.33 (4.95) bc

$816.75(7.46) \mathrm{d}$

$804.54(5.50) \mathrm{cd}$

$809.14(3.12) \mathrm{d}$

738.98 (16.37) ab

$750.36(6.30) \mathrm{a}$

$755.73(14.30) \mathrm{ab}$ $770.47(17.01) \mathrm{ab}$

\section{Silt and clay fraction $\mathrm{SC}<53 \mu \mathrm{m}$}

0

$129.97(3.10) b$

$119.70(8.88) \mathrm{a}$

$137.39(2.11) \mathrm{c}$

$123.29(2.75) b$

AC

109.05 (2.64) a

$107.38(1.67) \mathrm{a}$

102.86 (1.62) a

$106.91(2.91) \mathrm{a}$

LR

$104.17(5.14)$

$110.86(10.51) \mathrm{a}$

116.75 (2.97) b

$114.86(7.16) \mathrm{ab}$

LT

113.63 (6.68) ab

108.62 (6.60) a

$105.95(2.32) \mathrm{ab}$

$98.56(13.98) a b$

$\mathbf{L T}+\mathbf{A C}$

150.73 (13.86) b

162.79 (4.77) b

140.68 (11.93) abc

143.54 (10.64) b

$\mathbf{L T}+\mathbf{L R}$

134.35 (8.11) ab

$154.22(6.13) b$

146.36 (3.68) c

$145.31(12.81) \mathrm{ab}$ 
Mixed models (F and p-values)

$\begin{array}{llllllll}\mathbf{F} & \mathbf{p} & \mathbf{F} & \mathbf{p} & \mathbf{F} & \mathbf{p} & \mathbf{F} & \mathbf{p}\end{array}$

WSA $>2000 \mu \mathrm{m}$

$\begin{array}{lllllllll}\text { L. terrestris } & 39.35 & \underline{\mathbf{0 . 0 0 0 1}} & 0.32 & 0.582 & 0.10 & 0.758 & 0.55 & 0.471\end{array}$

$\begin{array}{lllllllll}\text { Other species } & 12.00 & \underline{\mathbf{0 . 0 0 1}} & 2.35 & 0.130 & 1.24 & 0.316 & 1.08 & 0.364\end{array}$

L. terrestris $\mathbf{x}$

Other species

$\begin{array}{llllllll}3.31 & 0.065 & 0.78 & 0.477 & 1.07 & 0.368 & 0.67 & 0.527\end{array}$

WSA 250 - $2000 \mu \mathrm{m}$

$\begin{array}{lrrrrrrrr}\text { L.terrestris } & 103.91 & \underline{\mathbf{\leq 0 . 0 0 0 1}} & 1.13 & 0.304 & 3.66 & 0.075 & 0.04 & 0.845 \\ \text { Other species } & 40.42 & \underline{\underline{\mathbf{0 . 0 0 0 1}}} & 1.07 & 0.368 & 5.50 & \underline{\mathbf{0 . 0 1 6}} & 1.74 & 0.210 \\ \begin{array}{l}\text { L.terrestris } \mathbf{x} \\ \text { Other species }\end{array} & 9.52 & \underline{\mathbf{0 . 0 0 2}} & 1.78 & 0.203 & 21.59 & \underline{\mathbf{0 0 . 0 0 0 1}} & 3.43 & 0.059\end{array}$

WSA 53 - $250 \mu \mathrm{m}$

$\begin{array}{lllllllll}\text { L. terrestris } & 42.91 & \underline{\mathbf{5 0 . 0 0 0 1}} & 76.08 & \underline{\mathbf{5 0 . 0 0 0 1}} & 1.23 & 0.284 & 8.27 & \underline{\mathbf{0 . 0 1 2}}\end{array}$

$\begin{array}{lllllllll}\text { Other species } & 0.26 & 0.777 & 76.22 & \underline{\mathbf{5 0 . 0 0 0 1}} & 42.03 & \underline{\mathbf{5 0 . 0 0 0 1}} & 3.01 & 0.080\end{array}$

\begin{tabular}{|c|c|c|c|c|c|c|c|c|}
\hline L. terrestris $\mathbf{x}$ & 15.24 & $<0.001$ & 12.23 & $<0.001$ & 48.18 & $<00001$ & 776 & 0005 \\
\hline
\end{tabular}

Silt and clay fraction $\mathrm{SC}<53 \mu \mathrm{m}$

\begin{tabular}{|c|c|c|c|c|c|c|c|c|}
\hline L. terrestris & 8.94 & $\underline{0.009}$ & 223.20 & $\leq 0.0001$ & 0.96 & 0.344 & 5.44 & $\underline{0.034}$ \\
\hline Other species & 8.37 & $\underline{0.004}$ & 14.81 & $\leq 0.001$ & 63.18 & $\leq 0.0001$ & 6.09 & $\underline{0.012}$ \\
\hline L. terrestris $\mathbf{x}$ & 8.21 & $\underline{0.004}$ & 20.52 & $\leq 0.001$ & 66.34 & $\leq 0.0001$ & 6.28 & $\underline{0.010}$ \\
\hline
\end{tabular}


710 Table 6-Summary of the outcomes of best fitted linear mixed model of earthworm-induced

711 porosity (percent of porosity in relation to total soil volume after correction for porosity of

712 control columns) after 61 days, as affected by different earthworm species and soil depth

713 (main factors: species (L. terrestris, A. caliginosa, or L. rubellus), soil depths: 2.5 to 10,10 to

71420,20 to 30 , and 30 to $35 \mathrm{~cm}$ soil depth). $\mathrm{N}=2$.

\begin{tabular}{lcccr}
\hline & \multicolumn{2}{c}{$\begin{array}{c}\text { Surface applied } \\
\text { crop residues }\end{array}$} & \multicolumn{3}{c}{$\begin{array}{c}\text { Incorporated crop } \\
\text { residues }\end{array}$} \\
\cline { 2 - 5 } & $\mathbf{F}$ & $\mathbf{p}$ & $\mathbf{F}$ & $\mathbf{p}$ \\
\hline Species & 0.91 & 0.429 & 5.27 & $\underline{\mathbf{0 . 0 2 5}}$ \\
Soil depth & 7.36 & $\underline{\mathbf{0 . 0 0 6}}$ & 6.03 & $\underline{\mathbf{0 . 0 1 1}}$ \\
Species x Soil depth & 0.11 & 0.994 & 1.29 & 0.339
\end{tabular}

715 


\section{Figure captions}

718 Figure 1 - Scheme of the experimental mesocosms, showing crop residue placement

719 treatments and earthworm treatments.

720 Figure 2 - Means and standard errors of earthworm-induced porosity (i.e. after correction for

721 porosity of earthworm-free treatments) averaged over earthworm treatments. A) crop residues

722 applied at the soil surface; B) crop residues incorporated between 20-30 cm depth. Different

723 letters depict pairwise significant differences at $p<0.05$ of porosity with soil depth layers.

724 “*” depict mean porosity values that are significantly different from 0 (one-tailed t-test). $\mathrm{N}=2$.

725 Figure 3 - Mean and standard error of earthworm-induced water stable aggregates (WSA) size

726 fractions (i.e. after correcting for WSA in earthworm-free control treatments), in treatments of

727 single $v s$. two-species of earthworms (grey and white bars, respectively), when crop residues

728 were surface-applied (panels A) or incorporated (panels B), per soil depth (0-20 (panels 1) and $729 \quad 20-30$ (panels 2) cm).

730 
Surface-applied treatments

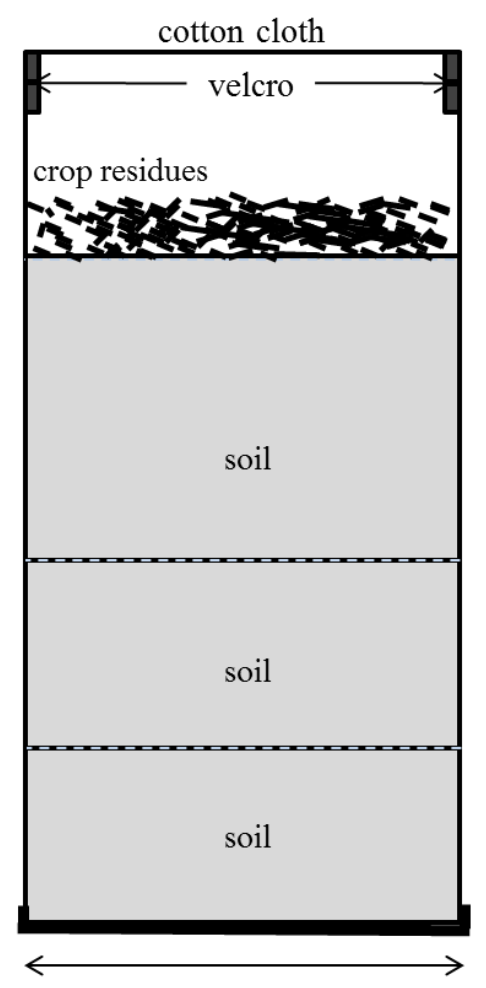

$19 \mathrm{~cm}$
Incorporated treatments

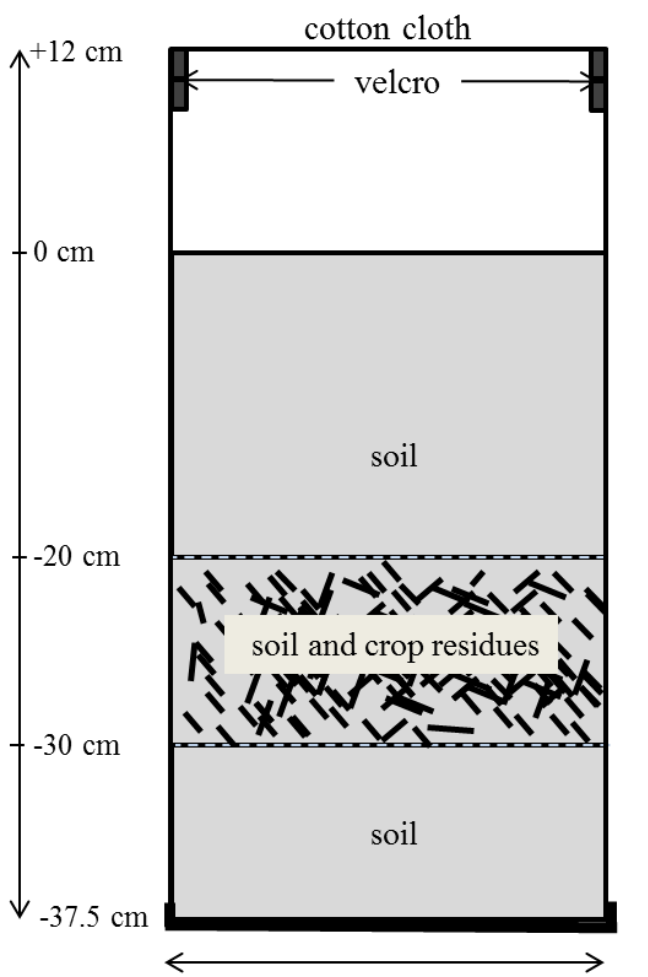

$19 \mathrm{~cm}$

\section{Earthworm treatments}

$0 \quad$ No earthworms

AC A. caliginosa

LR L. rubellus

LT L. terrestris

$\mathrm{LT}+\mathrm{AC} \quad$ L. terrestris $+A$. caliginosa

$\mathrm{LT}+\mathrm{LR} \quad$ L. terrestris $+L$. rubellus

\section{Figure 1 -}



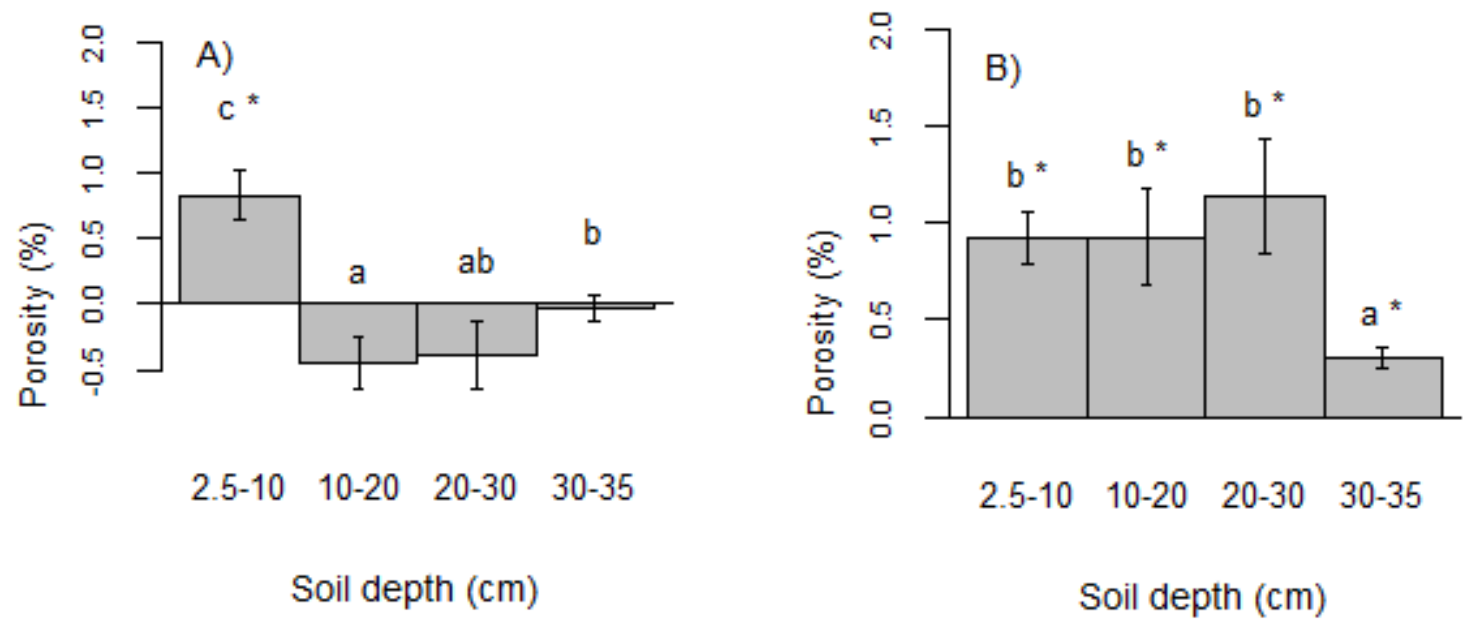

$735 \quad$ Figure 2 -

736 
A1) Surface crop

residues; depth $0-20 \mathrm{~cm}$

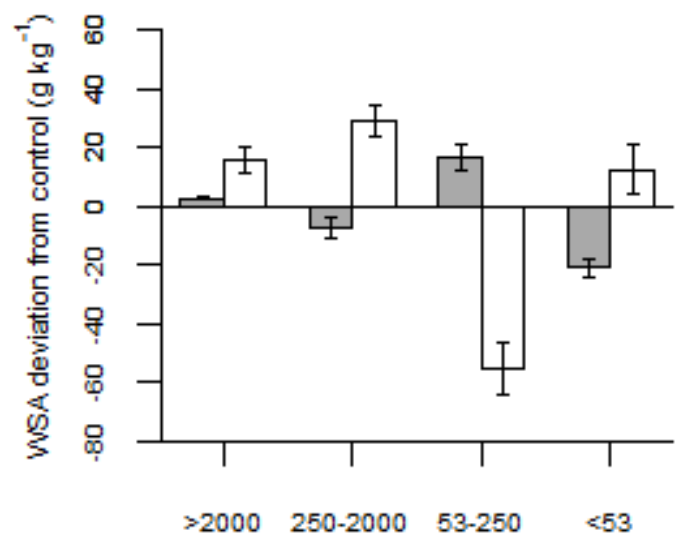

A2) Surface crop

residues; depth $20-30 \mathrm{~cm}$

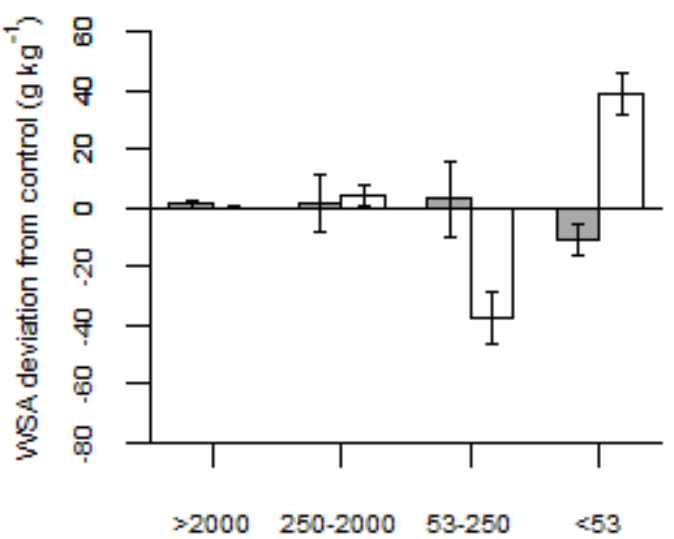

B1) Incorporated crop

residues; depth $0-20 \mathrm{~cm}$

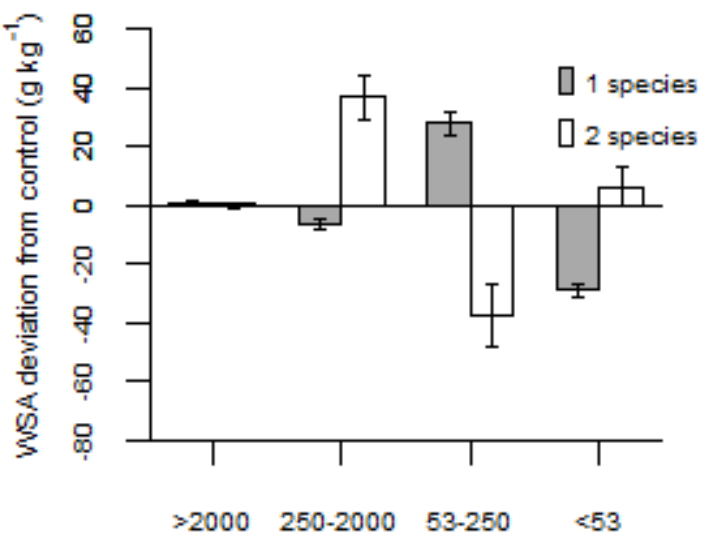

B2) Incorporated crop

residues; depth $20-30 \mathrm{~cm}$

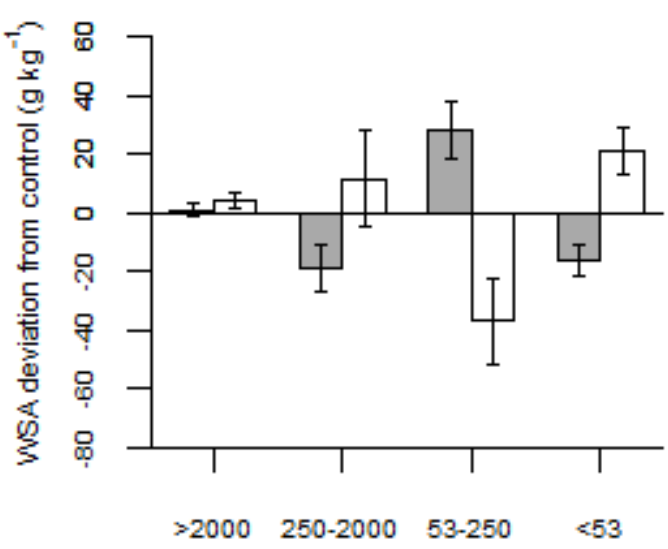

Figure 3 - 